\title{
The use of socionics in the motivation of personnel in agricultural enterprises
}

\author{
Sergey Yekimov ${ }^{1, *}$, Irina Kazachuk $^{2}$, Natalia Glukhikh $^{2}$, Larisa Shibakova $^{2}$, and Elena \\ Nemudraya $^{2}$ \\ ${ }^{1}$ Publishing House "Education and Science" s.r.o., Olstynska 607/1, Praha 8, 18100, Czech Republic \\ ${ }^{2}$ South Ural State Humanitarian Pedagogical University (SUSHPU), 69, Lenina Ave, Chelyabinsk, \\ 454080, Russia
}

\begin{abstract}
As a result of the transition to a remote method of work, some employees have reduced their motivation to carry out their professional duties and their work needs due to reduced control by the company's management. The employees ' responsibility for the work performed decreased somewhat. Some of them are experiencing stress and began to carelessly solve the current production duties, the deadlines for their implementation are lengthening. For the personnel of the enterprise, it may be characteristic to periodically reduce the level of motivation for their work, this has a negative impact on the level of their labor productivity. To effectively motivate employees, the head of the enterprise must have an individual approach to each member of the workforce. Understand how he thinks, perceives and evaluates the information received and how he can act in a particular situation. In our opinion, the compatibility of people in the labor collective is also of great importance in this matter.
\end{abstract}

\section{Introduction}

Productivity growth is important for agricultural enterprises. The search and identification of new opportunities, in our opinion, will enable the company to successfully develop, produce and sell more agricultural products. Agricultural production largely depends on the human factor.

In this regard, we believe that for the management of agricultural enterprises, an important role is played by the search and implementation of various methods of managing the company's labor resources in order to maximize the realization of their labor potential.

According to [1], the management of the enterprise's labor resources consists in the implementation of economic, organizational and social measures aimed at creating favorable conditions for the most productive use of the labor resources available to the enterprise.

According to [2], the personnel management system of an enterprise should include a mechanism for managing human resources in order to increase production efficiency and increase labor productivity .

According to [3], the management of the company's personnel can take place through

* Corresponding author : 3701313@mail.ru 
the use of psychological, economic, social and psychological methods.

According to [4], the system of motivation of employees of the enterprise should contain incentives that should take into account the characteristics of each employee individually. This is a certain list of actions performed by the company's management in order to increase the productivity of employees, attract and retain qualified specialists.

According to [5], a properly motivated employee receives moral satisfaction from the work duties performed by him.

According to [6], employee promotion is a complex process that requires accounting and analysis of the quality and quantity of labor.

The authors $[7,8,9]$ distinguish compensatory and non-compensatory systems of employee motivation (Figure 1):

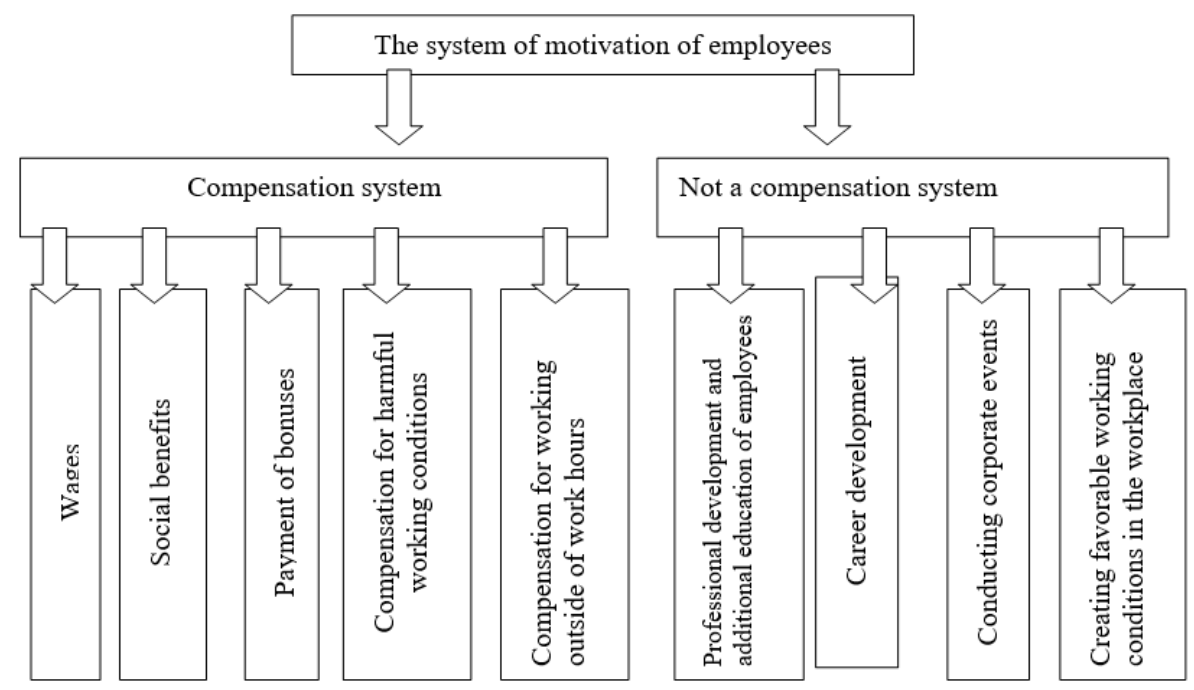

Fig. 1. The system of motivation of employees.

According to $[10,11]$, in order to achieve maximum efficiency from labor motivation, the company's personnel must clearly understand the goals and objectives facing the enterprise. The remuneration system should be transparent and understandable to all employees.

According to [12], the following types of employee motivation can be distinguished (Figure 2):

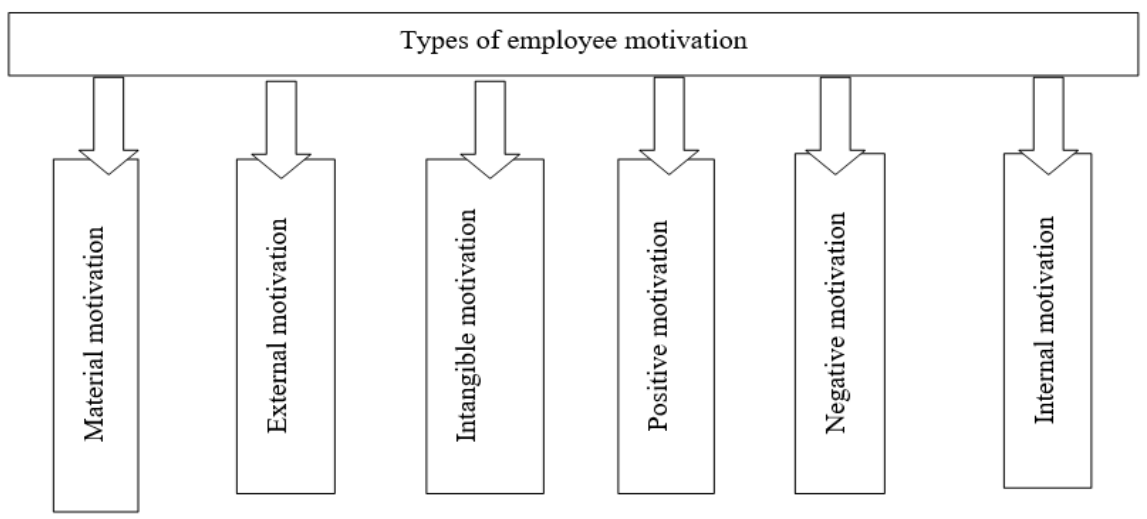

Fig. 2. Types of employee motivation. 
In our opinion, material motivation is a very effective method of stimulating the work of staff. However, its use has certain limitations. The payment of monetary remuneration increases the cost of production, and therefore the cost of production .Therefore, companies tend to use other types of motivation.

Non-material motivation provides for the creation of comfortable working conditions. The emotional bonuses and peace of mind that the employee receives stimulate the employee to a productive work activity. However, in our opinion, this type of motivation is not suitable for all employees. For example, employees working remotely arrange their own working conditions.

According to [13], internal motivation of the staff is important. The creative solution of production tasks can cause employees moral satisfaction for the achieved results.

According to [14], in order to be able to motivate a particular employee, it is advisable to find out his psychotype. This can be facilitated by socionics, a scientific concept that studies the types of personalities and their interaction with each other.

The authors [15] distinguish four types of intelligence, and also analyze possible variants of their behavior in the business environment:

1) The image. For people of this group, the prospect of career growth and the recognition of others is important.

2) Self-sufficiency. For people of this group, comfortable living conditions and wellbeing are of particular importance.

3) Well-being. These people are primarily focused on satisfying their desires

4) Uniqueness. This type of people experience discomfort when performing monotonous work.

\section{Methods}

When performing this research, we used an analytical method, which allowed us to study the problems considered in the article in their unity and development. Taking into account the tasks and goals of the research, we used the structural and functional method of scientific cognition. As a result, we were able to study a number of related problems and the use of socionics to motivate staff in agricultural enterprises.

\section{Results}

The reason for this research work was the appeal to us of the management of the agricultural enterprise "Kolos". The head of the enterprise noted that when switching to remote work for some employees, the decrease in control from the authorities served as a negative factor that reduced their efficiency and motivation to perform their work duties. The employees ' responsibility for the work done gradually decreased. Many of them begin to experience stress and be careless about the decision of the new production tasks and deadlines for their implementation.

We suggested using socionics methods to motivate the employees of Kolos LLC.

At the beginning of our research, with the knowledge of the company's management, we conducted a survey of the company's employees in order to find out what type of personality each individual employee belongs to.

As a result of the analysis, it was found out that $4 \%$ of the company's employees corresponded to the type of intelligence "prestige" among them were the majority of middle managers. $63 \%$ of the company's employees were of the "self-sufficiency" type of intelligence, which mainly included employees of the company over 45 years of age. $23 \%$ of the company's employees were assigned to the "uniqueness" type of intelligence. They 
included mostly employees of the company under 25 years of age. We attributed $10 \%$ of the company's employees to the "welfare" type of intelligence. They included mainly people with higher education (accounting workers, engineering and technical personnel.

Based on the results obtained, we suggested that employees with the "prestige" type of intelligence should be stimulated with smartphones of the latest models, so that they would receive moral satisfaction from assessing their importance to the enterprise.

For employees who belonged to the type of intelligence "self-sufficiency", we recommended to conclude health insurance contracts. Employees of this category understood that in this way they increased their social security and this further stimulated them for effective work.

For employees belonging to the type of intelligence "uniqueness", we suggested, if possible, to transfer to a remote type of work or assign them to solve non-standard production tasks.

For employees with the type of intelligence "welfare", we recommended the allocation of loans for the purchase of housing, vehicles or household appliances.

Based on the conducted research, we came to the conclusion that depending on what type of intelligence an employee belongs to, you can choose the required incentives for his productive work for a long period of time.

The modern labor market is experiencing a shortage of highly qualified specialists. Successful motivation of the company's staff will allow the manager to unite the workforce and save time needed to find new employees, as well as create conditions for employees to realize their potential.

\section{Discussion}

In modern HR management, motivational aspects are important. Motivation of employees of the enterprise allows to achieve the maximum efficiency of use of the labor potential of the enterprise. For agricultural enterprises in the conditions of rapid changes in the internal and external environment, in our opinion, it is very important to create a system of employee motivation that would correspond to the market conditions of the enterprise.

The personnel of the enterprise is its main production resource, which is of paramount importance for the successful functioning of the enterprise.

Therefore, there is a need to manage it skillfully and create the necessary conditions for its successful improvement. In our opinion, the efficiency of the staff of an agricultural enterprise largely depends on the existing system of remuneration incentives and the degree of motivation of its employees.

Motivation should be as transparent as possible to the staff, as well as have the flexibility to be able to stimulate various aspects of the successful work of employees.

The type of promotion, in our opinion, should have a psychological and economic justification.

In our opinion, the system of personnel incentives at the enterprise should contribute to the further growth of employees ' interest in improving their labor productivity. It is very important that there is a clear link between the results of work and the amount of remuneration received.

In our opinion, the system of stimulating and motivating the personnel of an agricultural enterprise should contain administrative, socio-psychological, economic-social, informational and production methods.

In our opinion, the system of labor motivation in the enterprise must meet the following requirements (Figure 3): 


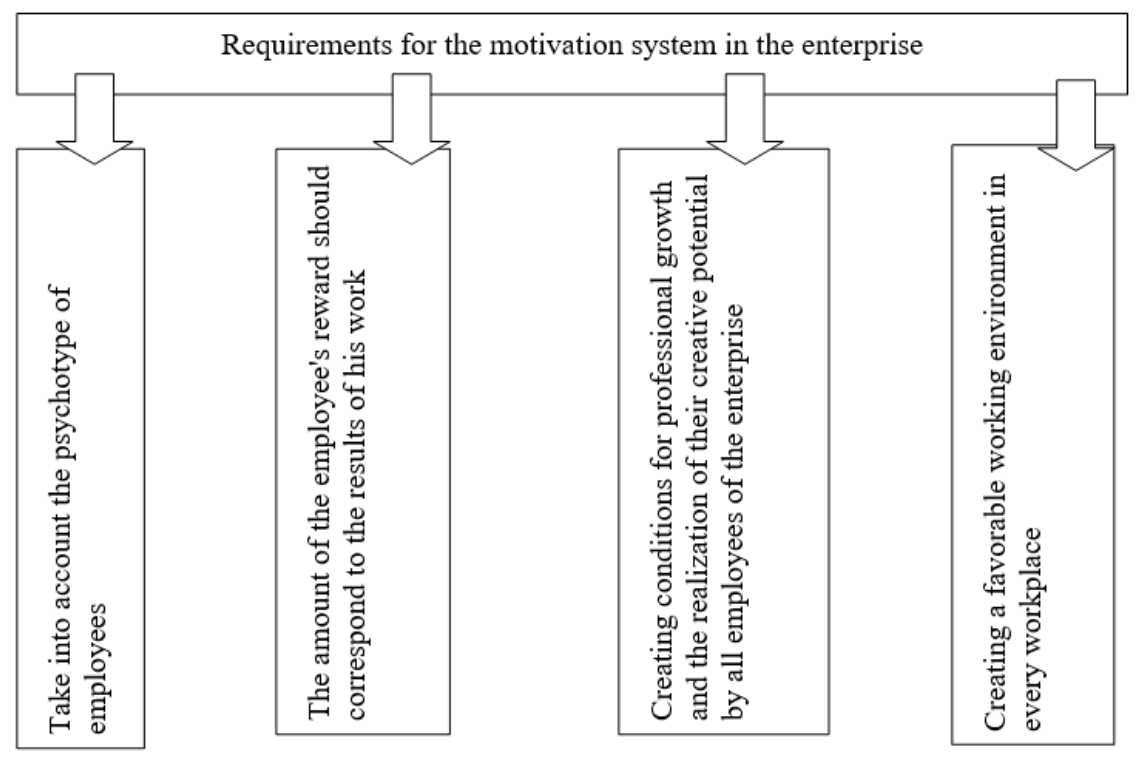

Fig. 3. Requirements for the motivation system in the enterprise.

Effective motivation of employees contributes to the formation of a reliable workforce consisting of like-minded people and professionals.

In our opinion, an important tool for motivating staff is salary, but the use of this type of motivation has certain limitations. Therefore, there is a need to use alternative methods of motivating labor activity. done.

The motivation of employees must be justified and correspond to the specific work

To achieve success in motivating employees, in our opinion, it is possible to study the personality characteristics of a particular employee, as well as his pisichotype.

\section{Conclusions}

In our opinion, motivation is a set of external and internal factors that have a motivating effect on any action. Every head of an agricultural enterprise wants to have qualified and hardworking employees, since the functioning and development of the enterprise depends on it. In order for employees to perform their work duties well, they need certain incentives: wages, career opportunities, moral or material benefits.

An effectively built system of personnel motivation allows you to significantly increase the effectiveness of their work, improve the quality of customer service. And at the same time, the lack of a system of employee motivation at the enterprise leads to a decrease in labor productivity at the enterprise and the accompanying negative consequences.

A poorly motivated employee may be negligent in the performance of their official duties, as well as seek to sweep away the place of work.

In our opinion, the motivation of human activity is a complex multi-faceted process that is inextricably correlated with the characteristics of the employee's personality. Motivation determines a person's behavior, and encourages him to achieve certain goals. In our opinion, it is important that these goals coincide with the interests of the enterprise.

The employee's attitude to the performance of their work duties and their behavior correlates with the working conditions and the associated remuneration.

In our opinion, the management of labor motivation should include economic, 
psychological, and social motives.

We believe that motivation should be based on an individual approach to each individual employee, taking into account the peculiarities of their value system and psychotype.

In our opinion, employee motivation is an integral component of the management activity of the head of the enterprise. Employees can have different goals for working in an enterprise. They may be interested in a career or just getting a salary.

For employees, it may be characteristic to periodically reduce the motivation for their work, which negatively affects their productivity. To effectively motivate the staff, the manager must have an individual approach to each employee. Understand how he thinks, evaluates and perceives the information received and how he can act in a particular situation. In our opinion, the compatibility of people in the labor collective is also of great importance in this matter.

\section{References}

1. Th. Nyoni, The impact of employee motivation on employee performance (2020)

2. I. Tasya, A. Gilang, Almana: Jurnal Manajemen dan Bisnis 4, 262-265 (2020) DOI: 10.36555/almana.v4i2.1405

3. M. Esteve, Ch. Schuster, Motivating Public Employees (2019) DOI: 10.1017/9781108559720

4. I. Rukmana, Almana: Jurnal Manajemen dan Bisnis 4, 190-196 (2020) DOI: 10.36555/almana.v4i2.1352

5. A. Asriani, D. Lorensa, F. Saputri, T. Hidayati, International Journal of Economics, Business and Accounting Research (IJEBAR) (2020) DOI: 4. 10.29040/ijebar.v4i01.933

6. E. Mitu, L. Comanescu, Motivation of Employees in the Public Institutions, 422-426 (2019) DOI: $10.35219 /$ rce2067053249

7. I. Svydruk, Scientific Bulletin of Kherson State University. Series Economic Sciences, 42-45 (2020) DOI: 10.32999/ksu2307-8030/2020-38-7

8. L. Lipych, O. Khilukha, M. Kushnir, et al., Economic journal of Lesia Ukrainka Eastern European National University 11, 32-39 (2017) DOI: 10.29038/2411-40142017-03-32-39.

9. P. Wulansari, A. Rahmi, The Effect of Employee Competence and Motivation on Employee Performance (2019) DOI: 10.2991/icebef-18.2019.146

10. L. Puyri, H. Pasaribu, The Effect of Leadership and Motivation on Employee Performance (2019) DOI: 10.4108/eai.8-10-2018.2289289

11. K. Talak, Pressacademia 11, 233-235 (2020) DOI: 10.17261/Pressacademia.2020.1275

12. S. Guinn, HR Review 12 (2013) DOI: 10.1108/shr.2013.37212baa.009

13. V. Holton, F. Dent, Jan. Rabbetts, Motivation and Employee Engagement in the $21 \mathrm{st}$ Century (2017) DOI:10.13140/RG.2.2.32041.60000.

14. L.V. Temnova, N.S. Faiman, RUDN Journal of Sociology 19, 7-19 (2019) DOI: 10.22363/2313-2272-2019-19-1-7-19

15. A. Bukalov, Management and personnel: psychology of management, socionics and sociology 2014, 21-36 (2014) 